Eigelb Verwendung gefunden haben, läßt sich die Bestimmung des Albumingehalts verwenden. Diese stützt sich auf die Tatsache, daß die pflanzlichen und tierischen. Globuline und der Kleber des Weizentorns in Wasser unlöslich sind, während das Albumin des Weißen vom $\mathrm{Ei}$ in kaltem Wasser löslich ist. In folgender Weise läbt sich das Albumin bestimmen: $30 \mathrm{~g}$ der gepulverten und durch ein Sieb von etwa $0,6 \mathrm{~mm}$ Maschenweite gesiebten Teigware werden mit $150 \mathrm{ccm}$ Wasser im Schüttelapparat eine halbe Stunde lang ausgeschüttelt. Nach erfolgter Klärung, die etwa binnen einer Stunde erreicht ist, wird die Flüssigkeit durch ein Wattebäuschchen filtriert, im Falle ungenügender Klärung jedoch vorher zentrifugiert. $20 \mathrm{ccm}$ des geklärten. Auszuges bringt man nun in ein Zentrifugiergläschen, dessen unterer, konischer Teil in $1 / 10 \mathrm{ccm}$ eingeteilt ist, erhitzt im Wasserbade steigend bis auf $80-85^{\circ}$, beläßt

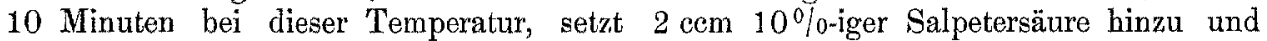
zentrifugiert sodann. Durch Vergleich des Volumens der Albuminfällung mit dem eines Typs von bekanntem Eigehalt wird die Höhe des Eizusatzes ermittelt.

\title{
E. Dinslage.
}

Utz: Über Eier-Fleisch-Teigwaren. (Pharm. Zentralh. 1912, 53, 35-36.) - Verf. hat ein Paket Riebelen der Firma Richard Gräbener in Karlsruhe untersucht, welche unter der Bezeichnung "Zipperer's Eier-Fleisch-Teigwaren" Suppeneinlagen in den Handel bringt, die nach Angabe des Herstellers aus feinstem Mehl unter Zusatz von etwa 600 Eiern auf $100 \mathrm{~kg}$ und einem mit Fleischsaft vermischten Gewürz in Form von Grieß, Riebeln, Finlauf, Flocken und Nudeln hergestellt werden. Die chemische Untersuchung ergab folgende Werte in Prozenten: Feuchtigkeit 6,64, Mineralstoffe 5,17 - vorwiegend Phosphate, davon Kochsalz 0,33, Fett 2,61, Stickstoffsubstanz 16,19, wasserlösliche Kohlenhydrate: geringe Spur, Lecithinphosphorsäure 0,09 , künstliche Färbung nicht nachweisbar. Verf. schließt aus diesem Ergebnis, dab Zipperer's Eier-Fleisch-Teigwaren gegenüber den gewöhnlichen Teigwaren und auch gegenüber den Eierteigwaren des Handels einen höheren Gehalt an Mineralstoffen, zum Teil auch an Fett, sodann hauptsächlich an Stickstoffsubstanz und an Lecithinphosphorsäure aufweisen.

P. W. Neumann.

\section{Honig.}

A. Sartory und Ed. Morean: Beitrag zur bakteriolgischen Untersuchung des Honigs. (Annal. des Falsific. 1911, 4, 259-263.) - Bei der Analyse der verschiedensten Honigsorten aus der Bretagne, Normandie, Cévennes, Gatinais konnten Verff. folgende Bakterien nachweisen, welche wohl von den Bienen aus der Luft aufgenommen und in die Körbe getragen sind: Bacillus subtilis, B. megaterium, B. aerophilus, Sarcina lutea, Micrococcus radiatus, Staphylococcus pyogenes und den Friedländer'schen Preumobacillus. Von Pilzen konnten isoliert werden: Penicillium glaucum, Rhizopus nigricans, Saceharomyces cerevisiae, Mucor racemosus, Aspergillus gracilis und Sterigmatocystes nigra. Außerdem wurde dreimal ein noch unbekannter Bacillus isoliert mit folgenden Eigenschaften: Unbewegliche Stäbchen 1,6-2,0 $\mu$ lang, $0,5 \mu$ breit. Bei Plattenkulturen entwickeln sich die Kolonien in schön goldgelben, zähen Scheiben, welche sich leicht von der Unterlage abheben lassen. Bei Stichkulturen verflüssigt sich die Gelatine sehr schnell. Die sich bildende klare Flüssigkeit ist mit einer flockigen, goldgelben Haut bedeckt. Bei Strichkulturen findet die Verflüssigung langsamer statt, die Kultur wird zunächst viscos, endlich verflüssigt auch sie sich und man beobachtet einen goldgelben Schleier durch die ganze Flüssigkeit. Auf Agar wächst der Bacillus pilzrasenartig, Kartoffeln werden von einer goldgelben Haut überzogen, auf Glycerin-Kartoffeln bildet sich eine hochgelbe Kultur ähnlich der von Staphylococcus aureus. Beim Altern geht die Färbung in Braun über. Auf Carotten ist das Wachstum sehr gut, auf Topinambur sehr schlecht. In Pepton- 
bouillon bildet sich innerhalb 3 Tagen ein gelber, dünner Schleier, der beim Umschwenken zu Boden sinkt. Außerdem ließ sich der Bacillus kultivieren in Lösungen von Lactose, Saccharose, Glykose, Maltose, auf Stärkekleister, Dextrin, Milch usw. Der gebildete Farbstoff ist sehr leicht löslich in absolutem Alkohol mit blaßgelber Farbe. Auf Zusatz von Alkalien schlägt die Färbung in Gelbbraun um. Durch Neutralisation regeneriert sich die gelbe Farbe, überschüssige Säure macht sie leuchtend gelb. Das Wachstumsoptimum liegt bei $30^{\circ}$. Bei dieser Temperatur wird auch am meisten Farbstoff gebildet. - Bei der biochemischen Untersuchung konnte Indol nicht nachgewiesen werden; Lactose, Dextrin und Stärke werden gar nicht, Saccharose nur minimal angegriffen. Die Verff. rangieren den neuen Bacillus zwischen Bacillus luteus Flügge und Bacillus flavus Mavé.

C. Grimme.

Léon Ronnet: Honig aus der Champagne. (Annal. des Falsific. 1911, 4, 427-429.) - Vollständige Analyse von 19 Honigsorten, 2 aus dem Jabre 1909, 17 aus 1910. Aus den in einer Tabelle zusammengestellten Analysenwerten läbt sich folgendes schließen: Sämtliche Honige sind vor und nach der Inversion linksdrehend $\left(1,22-2,20^{\circ}\right.$ vor und $1,40-2,32^{0}$ nach der Inversion). Saccharose 0,19 bis 5,83\%, Gesamt-Zucker 76,95-84,21\%. Der Wassergehalt war stets unter $20 \%$, die Asche im Maximum $0,28 \%$. Der Säuregehalt war sehr niedrig, im Höchstfalle = $0,092 \%$ Ameisensäure. Gesamt-Protein war stets unter $0,35 \%$, die Tanninfällung nach Lund schwankte zwischen 1 und 1,6 ccm. Die Fiehe'sche Reaktion war stets negativ.

C. Grimme.

M. Nyman und A. Wichmann: Über die Resorcinprüfung bei der Honiguntersuchung. (Pharmazeut. Notizblatt, Helsingfors 1909 Sonderabdruck.) - Verf. berichtet über seine Erfahrungen mit der Fiehe'schen Reaktion auf Invertzucker bei Handelshonigen. Er untersuchte 34 Honige meist finnisehen, auch deutschen, schwedischen und amerikanischen Ursprunges, die als garantiert rein bezeichnet worden waren, daneben auch 2 Kunsthonige, sowie Mischungen von reinem Honig mit 5 bis $40 \%$ Kunsthonig. Bei keinem der erstgenannten Honige wurde eine positive Reaktion. nach Fiehe beobachtet. Auch durch Erhitzen des Honigs eine Stunde hindurch auf $100^{\circ}$ oder 20 Minuten auf $200^{\circ}$ können Täuschungen nicht entstehen; bei noch schwächerem Erhitzen entsteht mit Fieh e'schem Reagens keine Färbung, bei stärîerem Erhitzen aber eine grünviolette Färbung, jedoch ist solcher Honig earamelisiert und dunkelbraun. Bei Mischungen sind die Reaktionen nicht sonderlich charakteristisch. Man nimmt die Reaktion am besten mit Salzsäure vom spezifischen Gewicht 1,19 vor und läßt den Äther auf dem Wasserbade verdunsten.

A. Behre.

C. Reese: A bnormer Honig. (Bericht des Untersuchungşamtes Kiel 1911, 12-13.) - Von einem Bienenstand aus der Nähe einer Bonbonfabrik wurde eine Wabe erhalten, deren Zellen mit reifem Honig gefüllt und zum größten Teil bedeckelt waren. Die Wachsteile wie der eingelagerte Honig boten ein buntes Bild. Ganze Komplexe der Wabe waren teilweise rot, teilweise gelb gefärbt oder hatten die Mischfarbe orange angenommen. Die Wabe wurde entdeckelt und der Honig bei $40^{\circ}$ ausgelassen. Er war braunrot; sein Geruch wenig aromatisch, der Geschmack sirupartig. Die schwach fhoreszierende wässerige Lösung zeigte nach kurzem Stehen einen geringen Bodensatz, der neben wenig Pollenkörnern zahlreiche Körnchen von Maisstärke enthielt. Die Untersuchung ergab: Spez. Gewicht der Lösung $1+2=1,1169$; Wasser 18,01, direkt reduzierender Zucker als Invertzucker 68,85, Saccharose 4,35\%; Polarisation der Lösung 1:10 vor Inversion t-0,61, nach Inversion t $0,28^{\circ}$. Reaktion nach Fiehe auf Invertzucker negativ, auf Stärkezucker sehr schwach milchig. Reaktion nach Ley rotbraun mit gelbgrünem Schimmer. Fällung nach Lund 1,1 cem. Künstlicher Farbstoff vorhanden; Wollfaden orange. Eine Trennung und Fixierung der an 
der Wabe sichtbaren gelben und roten Farbstoffe gelang nicht vollständig; nachdem ein Orangefarbstoff durch Wolle vollständig ausgezogen war, verblieb in der Lösung ein roter Farbstoff, der nicht auf Wolle ging. Hiernach dürfte die Vermutung nicht zweifelhaft sein, daß der Honig wesentlich durch Naschen der Bienen an den in der Bonbonfabrik vorhandenen, künstlich gefärbten Zuckerarten beeinflußt war. C. Mai.

Gustar Neuhoff: Honiguntersuchung. (Bericht des Untersuchungsamtes Dortmund 1911, 17-18.) - Die Reaktion nach Fiehe tritt bei reinen Honigen, auch wenn diese in der üblichen Weise, sowie auch auf $80-100^{\circ}$ längere Zeit erhitzt wurden, nicht ein; sie ist aber nur dann als positiv anzusehen, wenn sowohl mit $25 \%$-iger wie auch mit $38 \%$-iger Salszäure die charakteristische, dunkelkirschrote Färbung erbalten wird, die sich mindestens 30 Stunden lang beständig erhält. Bei derart positivem Ausfall der Reaktion kann ein Honig ohne weiteres als mit technischem Invertzucker verfälscht angesprochen werden. Die Reaktion nach Jägerschmidt fällt nur dann positiv aus, wenn auch die nach $\mathrm{Fi}$ iehe positiv war.

C. Mai.

\section{Kaffee, Kakao, Tee.}

James Burmann: Gen aue Methode zur Bestimmung des Coffeins in Tee, rohem und geröstetem Kaffee. (Annal. des Falsific. 1911, 4, 99-101.) - Verf. bespricht die bekannteren Verfahren zur Bestimmung des Coffeins und gibt sodann folgende Methode: $5 \mathrm{~g}$ fein gemahlener Kaffee werden im Wassertrockenschrank bis zur Gewichtskonstanz getrocknet. Verlust $\times 20=\%$ Feuchtigkeit. Das trockne Pulver wird in einem $100 \mathrm{ccm}-E r l e n m e y e r-K o l b e n ~ m i t ~ 50 \mathrm{cem}$ Petroläther (Sdp. $\left.60^{\circ}\right) 10$ Minuten lang geschüttelt, die Lösung abfiltriert und der Rückstand nochmals mit $25 \mathrm{ccm}$ Petroläther ausgezogen, Unlösliches wird mit Petroläther auf das Filter gebracht. Die vereinigten Filtrate werden in gewogenem Kolben verdampft, der Rückstand bei $100^{\circ}$ getrocknet und gewogen. Gewicht $\times 20=\%$ Fett. Das entfettete Pulver wird lufttrocken in einem verschlossenen $200 \mathrm{cem}-\mathrm{Kolben}$ mit $150 \mathrm{~g}$ Chloroform einige Minuten lang geschüttelt, dann gibt man $5 \mathrm{~g} \mathrm{10 \%} / 0$-iges Ammoniak hinzu und schüttelt ${ }^{1 / 2}$ Stunde lang kräftig und häufig durch, filtriert das Lösungsmittel unter Bedecken des Trichters mit einem mit Chloroform angefeuchteten Filter ab und destilliert aus gewogenem Kolben ab. Getrockneter Rückstand $\times 20=0 \%$ Rohcoffein. Die Reinigung geschieht mittels Sublimation. Man löst das Rohcoffein in wenig Chloroform, spült die Lösung quantitativ in ein $15-18 \mathrm{~cm}$ langes, $1,5-1,8 \mathrm{~mm}$ weites Reagensglas, welches an 2 Stellen verengt ist (Abbildung siehe Original), verdampft das Lösungsmittel und trocknet bei $100^{\circ}$ oder im Vakuum. Darauf wird die untere Verengerung lose mit gewaschenem Asbest verschlossen und die obere Öffnung mit einem Wattebausch; man hängt das ganze bis über die untere Verengung in ein Paraffinbad und erhitzt vorsichtig auf $210-210^{\circ}$. Das Coffein sublimiert. Nach etwa 3 Stunden ist die Operation beendigt. Man schneidet nach dem Erkalten an der unteren Verengung durch, löst das Sublimat in wenig Chloroform, verjagt letzteres und trocknet den Rückstand bis zur Gewichtskonstanz. Gewicht $\times 20+0,0025=0 \%$ Reincoffein. Eine zweite Sublimation liefert reinstes Coffein vom Schmelzpunkt $234^{\circ}$. Die Methode eignet sich auch zur Bestimmung von Coffein in Tee, Maté, Kolanüssen usw. C. Grimme.

P. de Lylle: Verfahren zur Unterscheidung der Auszüge von Tee und Mate. (Annal. Chim. analyt. 1912, 17, 84.) - Auszüge von Tee unterscheiden sich von denjenigen des Maté dadurch, daß erstere blaßbraun, letztere hellgrün sind. Weitere Unterschiede sind vorhanden in ihrem Verhaiten gegen Reaganzien wie Ammoniak, Quecksilbernitrat, Kalkwasser, Kaliumquecksilberjodid, Sodalauge, Magnesiamixtur, Silbernitrat, Phenolphthalein, Bleiessig und Zinksulfat, womit Teeauszüge meist 